\title{
Proton Transfer in Strong Hydrogen Bonds Revealed by Infrared Spectra - Correlations between Structure and Spectra for the $\mathrm{BrH}: \mathrm{NH}_{3}$ Complex
}

\author{
K. Szczepaniak and W.B. Person \\ Department of Chemistry, University of Florida \\ P.O. Box 117200, Gainesville, Florida, 32611, USA
}

\section{Dedicated to the memory of our good friend Jerzy Prochorow}

One of our most pleasant memories is of the afternoon during our last visit in Poland spent walking and talking with Jerzy and Halina P. in Wilanów Park. One topic of that conversation concerned the possibility of sending him a manuscript for possible publication in Acta Physica Polonica A. It has been a disappointingly slow process, but we humbly and belatedly offer this to honor his memory.

\begin{abstract}
Our scope is to achieve an understanding of the relation between the infrared spectrum and structure of a strong hydrogen-bonded complex, $\mathrm{BrH}$ : $\mathrm{NH}_{3}$, and how and why this relationship is affected by the environment surrounding the complex. A series of DFT/B3LYP/6-31G(d,p) calculations was carried out for this system to obtain its structure and spectrum in different dielectric fields characterized by their relative permittivities. Changes in structure and spectrum (both frequencies and intensities) as the relative permittivity changes are explored. Calculations of spectra are made first under the harmonic approximation. In the next step the effect of anharmonicity was estimated for several different dielectric fields. The calculated anharmonic spectrum (for $\varepsilon_{\mathrm{r}}=1.6$ ) is compared with the experimentally observed infrared spectrum of the complex isolated in an Ar matrix at $10 \mathrm{~K}$, obtained in our laboratory. The calculated frequencies and relative intensities for all normal modes agree with the corresponding experimental data surprisingly well. The potential usefulness of structure-spectra correlations is explored.
\end{abstract}

PACS numbers: 82.30.Rs, 33.20.Ea, 33.70.Fd, 31.15.Ew, 33.20.Tp 


\section{Introduction}

Hydrogen bonds between proton donors and proton acceptors play an essential role in determining the properties of molecular systems, including those in living organisms. The infrared spectrum is very sensitive to the position of the proton and may provide quantitative information about the geometry of the complex, when combined with quantum mechanical calculations. Use of matrix isolation in noble gas solids offers a unique opportunity to study spectra over the entire mid-infrared region (no interfering absorption from the solvent) which is often of crucial importance for strongly hydrogen bonded complexes. In this paper we focus our attention on the hydrogen bond between the strong acid hydrogen bromide $(\mathrm{HBr})$ and the base ammonia $\left(\mathrm{NH}_{3}\right)$, abbreviated in the following text by $\mathrm{BrH}_{\mathrm{b}}: \mathrm{NH}_{3}$ (the "b" subscript designates the atom involved in the hydrogen

bond). It is one of the simplest examples of a strong hydrogen bond in which proton transfer from $\mathrm{BrH}_{\mathrm{b}}$ to $\mathrm{NH}_{3}$ is promoted by the environment. Although we are focusing on this particular system, we believe that the results presented below will be useful in understanding properties - particularly infrared spectra including intensities — of hydrogen bonded complexes in general.

Any interaction of the hydrogen bonded complex with its surrounding may cause changes in the structure and spectra of the complex from those found in the gas phase (see recent papers and references therein [1-5]). In this work we consider changes in the hydrogen bonded complex that are caused by the reaction field in a dielectric medium. Recent studies (e.g. [1-5]) indicate that this effect is very dramatic.

We carried out quantum-mechanical calculations of structure and infrared spectra of the $\mathrm{BrH}_{\mathrm{b}}$ : $\mathrm{NH}_{3}$ complex over a range of dielectric fields of varying strength characterized by the relative permittivity (dielectric constant) $\varepsilon_{\mathrm{r}}$. These calculations provide data on changes of geometry and spectra (frequencies and intensities) as well as the description of the normal modes and allow examination of trends in the correlations between the structural and spectroscopic parameters. The results are very helpful in the interpretation of experimental spectra (particularly the observed intensity patterns) of the $\mathrm{BrH}_{\mathrm{b}}: \mathrm{NH}_{3}$ complex isolated in low temperature matrices formed of solid noble gases or of solid $\mathrm{N}_{2}$, including studies from our laboratory.

The studies reported here are an extension of earlier attempts to combine results from quantum-mechanical calculations with experimental study of vibrational spectra of matrix-isolated molecules and complexes (for example see [6-10]). In this paper we carry out density functional theory (DFT) calculations (see references 19-21 in [8]), which are capable of providing good values for vibrational frequencies and intensities at a considerably lower computational cost and our time than for post-HF methods as used in [6] and [7]. 


\section{Quantum-mechanical calculations of the effect of dielectric field on the properties of $\mathrm{BrH}_{\mathrm{b}}: \mathrm{NH}_{3}$}

The effect on the structure and infrared spectra that occurs for hydrogen bonded complexes in a dielectric medium is evaluated using the Onsager model for the field effect with Gaussian program G98W [11]. The calculations were carried out on a Personal Computer (Dell 8300 under Windows XP Professional) at the DFT B3LYP/6-31G(d,p) level of theory. The details and references for these DFT calculations were described in [8], as were those concerning the analysis of the calculated data by other programs developed for use in our laboratory (ANIMOL for visualizing the normal coordinate displacements, XTRAPACK for calculating potential energy distributions and intensity distributions, and Anharmonic program in MathCad ${ }^{\text {tr }}$ to calculate the correction for anharmonicity). In this paper we shall not repeat these previous descriptions.

\subsection{Effect of dielectric field on structure}

The hydrogen bond in $\mathrm{BrH}_{\mathrm{b}}: \mathrm{NH}_{3}$ is linear, imposing constraints on the distances $\left(R\left(\mathrm{BrH}_{\mathrm{b}}\right)+R\left(\mathrm{H}_{\mathrm{b}} \mathrm{N}\right)=R(\mathrm{NBr})\right)$ and the angle $\left(A\left(\mathrm{BrH}_{\mathrm{b}} \mathrm{N}\right)=180^{\circ}\right)$. The $C_{3 v}$ symmetry of the complex imposes further constraints, so that the structure is described by values of 6 independent coordinates; namely $R\left(\mathrm{BrH}_{\mathrm{b}}\right), R\left(\mathrm{H}_{\mathrm{b}} \mathrm{N}\right)$, $R\left(\mathrm{NH}_{i}\right), A\left(\mathrm{BrH}_{\mathrm{b}} \mathrm{N}\right), A\left(\mathrm{H}_{\mathrm{b}} \mathrm{NH}_{i}\right)$ and $A\left(\mathrm{H}_{i} \mathrm{NH}_{j}\right)$ ( $i$ and $j$ relate to the hydrogen atoms of the $\mathrm{NH}_{3}$ fragment).

Values for the equilibrium distances most sensitive to the change of the environment $\left(R\left(\mathrm{BrH}_{\mathrm{b}}\right), R\left(\mathrm{H}_{\mathrm{b}} \mathrm{N}\right), R(\mathrm{NBr})\right)$ are shown in Table I. These results are from calculations B3LYP/6-31G(d,p) using self-consistent reaction field (SCRF) model (key words: SCRF = DIPOLE; OPT = Tight; at a calculated cavity radius of $3.21 \AA[11])$. The values of the relative permittivity $\varepsilon_{\mathrm{r}}$ in the table are from 1.00 to 7.00, covering the range from gas phase to solid $\mathrm{NH}_{4} \mathrm{Br}$.

Each row in Table I lists properties of the equilibrium structure found in the SCRF calculation for the complex in the field with relative permittivity $\varepsilon_{\mathrm{r}}$. As can be seen in the table, the values for the properties are quite sensitive to $\varepsilon_{\mathrm{r}}$, particularly in the range from 1.0 to 2.0, where major structural changes are found for small changes of $\varepsilon_{\mathrm{r}}$. For $\varepsilon_{\mathrm{r}}$ greater than 2.0, the changes in structure are much more gradual so that wider intervals for $\varepsilon_{\mathrm{r}}$ are sufficient to show trends there.

It is instructive to present some of the results listed in Table I in terms of correlation diagrams showing the trends in changing of the properties with the relative permittivity of the environment. Figure 1 shows the correlation of $R\left(\mathrm{BrH}_{\mathrm{b}}\right)$ and $R\left(\mathrm{NH}_{\mathrm{b}}\right)$ with $\varepsilon_{\mathrm{r}}$ (from 1.00 to 7.00 ). Figure 2 shows a similar correlation diagram for the $R(\mathrm{BrN})$.

The abrupt change of $R\left(\mathrm{BrH}_{\mathrm{b}}\right)$ and $R\left(\mathrm{NH}_{\mathrm{b}}\right)$ distances in Fig. 1 and of $R(\mathrm{NBr})$ in Fig. 2 identifies the proton transfer reaction occurring for $\varepsilon_{\mathrm{r}}$ between 1.472 and 1.475 , marking a transition region from the neutral-molecule structure 
TABLE I

Calculated equilibrium distances (in $[\AA]) R_{\mathrm{e}}(\mathrm{BrH}), R_{\mathrm{e}}(\mathrm{NH})$ and $R_{\mathrm{e}}(\mathrm{NBr})$ of $\mathrm{BrH}_{\mathrm{b}}: \mathrm{NH}_{3}$ complex in different dielectric field characterized by relative permittivity $\varepsilon_{\mathrm{r}}$.

\begin{tabular}{|c|c|c|c|}
\hline$\varepsilon_{\mathrm{r}}$ & $R_{\mathrm{e}}(\mathrm{HBr})$ & $R_{\mathrm{e}}(\mathrm{NH})$ & $R_{\mathrm{e}}(\mathrm{NBr})$ \\
\hline 1.000 & 1.5108 & 1.6516 & $3.1624^{a}$ \\
\hline 1.100 & 1.5199 & 1.6243 & 3.1442 \\
\hline 1.200 & 1.5307 & 1.5957 & 3.1264 \\
\hline 1.240 & 1.5352 & 1.5838 & 3.1190 \\
\hline 1.300 & 1.5438 & 1.5642 & 3.1080 \\
\hline 1.350 & 1.5511 & 1.5451 & 3.0970 \\
\hline 1.400 & 1.5609 & 1.5246 & 3.0855 \\
\hline 1.450 & 1.5759 & 1.4935 & 3.0694 \\
\hline 1.460 & 1.5812 & 1.4843 & 3.0655 \\
\hline 1.465 & 1.5847 & 1.4782 & 3.0629 \\
\hline 1.470 & 1.5879 & 1.4722 & 3.0600 \\
\hline 1.472 & 1.5897 & 1.4689 & 3.0586 \\
\hline 1.475 & 1.6564 & 1.3664 & 3.0228 \\
\hline 1.480 & 1.6648 & 1.3551 & 3.0198 \\
\hline 1.500 & 1.6832 & 1.3310 & 3.0142 \\
\hline 1.520 & 1.6957 & 1.3156 & 3.0113 \\
\hline 1.550 & 1.7110 & 1.2978 & 3.0088 \\
\hline 1.600 & 1.7322 & 1.2750 & 3.0072 \\
\hline 1.630 & 1.7436 & 1.2637 & 3.0073 \\
\hline 1.650 & 1.7507 & 1.2570 & 3.0076 \\
\hline 1.700 & 1.7671 & 1.2422 & 3.0093 \\
\hline 1.800 & 1.7946 & 1.2202 & 3.0148 \\
\hline 1.900 & 1.8154 & 1.2046 & 3.0200 \\
\hline 2.000 & 1.8316 & 1.1936 & 3.0252 \\
\hline 2.200 & 1.8575 & 1.1774 & 3.0349 \\
\hline 2.500 & 1.8870 & 1.1611 & 3.0480 \\
\hline 3.000 & 1.9259 & 1.1429 & 3.0688 \\
\hline 5.000 & 2.0536 & 1.1040 & 3.1576 \\
\hline 7.000 & 2.1584 & 1.0854 & 3.2438 \\
\hline
\end{tabular}

${ }^{a}$ Experimental $R(\mathrm{NBr})=3.255 \AA$ A, Ref. A.C. Legon, Chem. Soc. Rev. 22, 153 (1993).

$\left(\mathrm{BrH}_{\mathrm{b}}: \mathrm{NH}_{3}\right)$ to the ion-pair structure $\left(\mathrm{Br}^{-}: \mathrm{H}_{\mathrm{b}} \mathrm{NH}_{3}^{+}\right)$(the ammonium ion bonds through one of its $\mathrm{N}-\mathrm{H}$ bonds to a bromide ion, with $C_{3 v}$ symmetry). 

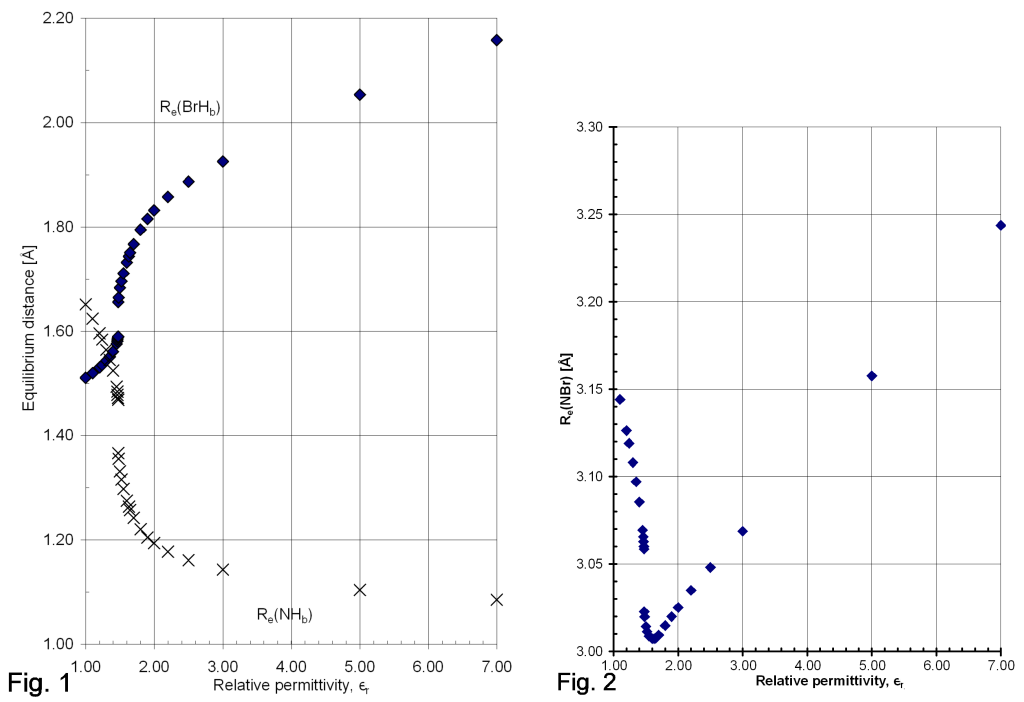

Fig. 1. Correlation of the calculated equilibrium distances $R_{\mathrm{e}}(\mathrm{BrH})-$ filled diamonds and $R_{\mathrm{e}}(\mathrm{NH})$ - crosses with $\varepsilon_{\mathrm{r}}$, for $\mathrm{BrH}: \mathrm{NH}_{3}$.

Fig. 2. Correlation of the calculated equilibrium distance $R_{\mathrm{e}}(\mathrm{NBr})$ of the $\mathrm{BrH}: \mathrm{NH}_{3}$ complex with $\varepsilon_{\mathrm{r}}$.

\subsection{Effect of dielectric field on infrared spectra}

The DFT calculations described in the previous section using the Onsager model to obtain the optimized geometry for the $\mathrm{BrH}_{\mathrm{b}}$ : $\mathrm{NH}_{3}$ complex were extended to carry out calculations of the frequencies and intensities for the eight (4 in the $a_{1}$ symmetry class and 4 doubly degenerate modes in the $e$ class) normal modes that define the infrared spectrum of the complex in the different environments characterized by $\varepsilon_{\mathrm{r}}$. Because of the $C_{3 v}$ symmetry, the internal coordinates of $a_{1}$ symmetry do not interact with those of $e$ symmetry.

The calculation is made assuming first that the potential energy is harmonic. The possible effects due to anharmonicity will be discussed in Sect. 2.3.

The names of the normal modes for the complex vary by author, but the usual practice is to use names that describe the predominant internal symmetry coordinate for each vibration of the isolated complex. We shall use the following names or abbreviations given below in parentheses for the four $a_{1}$ modes: $\nu 1-$ $\mathrm{NH}_{3}$ symmetric stretch $\left(\mathrm{NH}_{3} \mathrm{~s}\right.$ str); $\nu 2$ - hydrogen bonded proton stretch $(\mathrm{P}$ str $)$; $\nu 3-\mathrm{NH}_{3}$ umbrella bend $\left(\mathrm{NH}_{3} \mathrm{umb}\right)$; and $\nu 4$ - dimer stretch (Di str). For the four doubly degenerate $e$ normal modes: $\nu 5-\mathrm{NH}_{3}$ asymmetric stretch $\left(\mathrm{NH}_{3}\right.$ as str); $\nu 6-\mathrm{NH}_{3}$ asymmetric deformation $\left(\mathrm{NH}_{3}\right.$ as def $) ; \nu 7-\mathrm{BrH}_{\mathrm{b}} \mathrm{N}$ bend; and $\nu 8-\mathrm{NH}_{3}$ rock. 


\subsubsection{Normal modes of $a_{1}$ symmetry}

Table II lists the frequencies of the $a_{1}$ normal modes $(\nu 1, \nu 2, \nu 3$, and $\nu 4)$ of the $\mathrm{BrH}_{\mathrm{b}}$ : $\mathrm{NH}_{3}$ complex in different dielectric fields. Each row in Table II lists values for all 4 normal modes from the SCRF calculation for the Onsager dielectric field characterized by the value of $\varepsilon_{\mathrm{r}}$ given in the first column. The frequencies and intensities of each normal mode are listed in alternating columns across the table. For comparison the corresponding data for the vibrations of $\mathrm{HBr}, \mathrm{NH}_{3}$, and $\mathrm{NH}_{4}^{+}$monomers calculated at the same level of theory (for $\varepsilon_{\mathrm{r}}=1$ ) are listed in the footnotes of Table II. It should be noted that use of the word "intensity" or "intensities" in this paper is an abbreviation for the longer IUPACrecommended term: "integrated absorption intensity A (against wave number) in units of $\mathrm{km} \mathrm{mol}^{-1} "$ [12].

The effect of the dielectric field on the frequency and intensity of each normal mode of the complex can be seen by scrolling down the corresponding columns in Table II. This examination shows that the frequency of normal mode $\nu 1\left(\mathrm{NH}_{3} \mathrm{~s}\right.$ str) does not change very much (by less than $1.5 \%$ for a change of $\varepsilon_{\mathrm{r}}$ from 1.0 to 7.0). The intensity changes from 5 to $110 \mathrm{~km} \mathrm{~mol}^{-1}$.
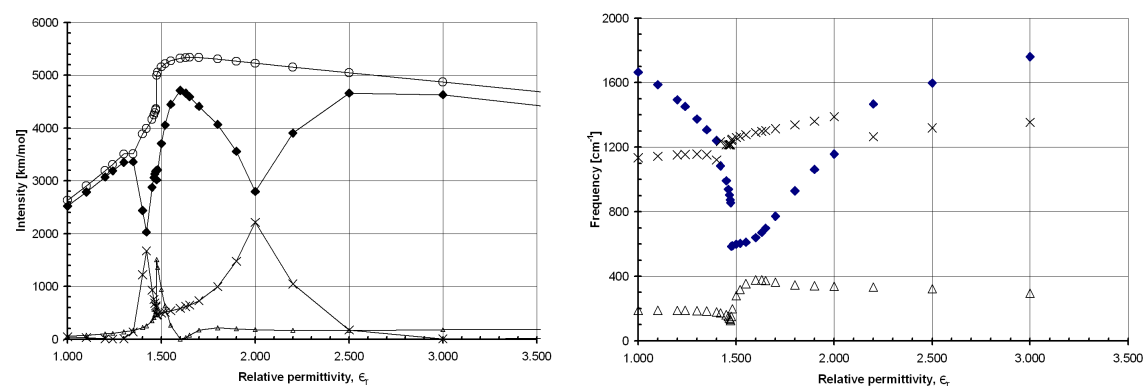

Fig. 3. Correlation with $\varepsilon_{\mathrm{r}}$ : right part — calculated frequencies of the normal modes $\nu 2$ - filled diamonds; $\nu 3$ - crosses; $\nu 4$ - triangles; left part — calculated intensities $A 2$ - filled diamonds; $A 3$ - crosses; $A 4$ - triangles; total intensity $(A 1+A 2+A 3+A 4)$ - circles.

The values for the other three $a_{1}$ normal modes are much more affected by the change of the field, as seen in Table II and Fig. 3. In Fig. 3 (right) correlation diagrams of the frequencies $\nu 2, \nu 3$, and $\nu 4$ with $\varepsilon_{\mathrm{r}}$ are shown. Figure 3 (left) presents the corresponding correlation for the intensities $(A 2, A 3$, and $A 4)$. (The diagram does not include $\nu 1$ because changes for it are quite small.)

There is a smooth decrease in the frequency of $\nu 2$ and increase in its intensity (with little change in frequency and intensity for $\nu 3$ or $\nu 4$ ) until $\varepsilon_{\mathrm{r}}$ is somewhere between 1.35 and 1.42, where the frequency of $\nu 2$ approaches that of $\nu 3$. For $\varepsilon_{\mathrm{r}}$ between 1.35 and 1.48 dramatic decreases of both frequency and intensity of $\nu 2$ occur, accompanied by a strong increase in intensity for the $\nu 3$ mode. These changes reflect the changing character of the normal modes; as seen in Fig. 4. 
TABLE II

Calculated frequencies $-\nu i-$ in $\left[\mathrm{cm}^{-1}\right]$ and intensities $-A i$ in $[\mathrm{km} / \mathrm{mol}]$ of normal modes of $a_{1}$ symmetry of $\mathrm{BrH}_{\mathrm{b}}: \mathrm{NH}_{3}$ complex in different dielectric field characterized by relative permittivity $\varepsilon_{\mathrm{r}}$.

\begin{tabular}{|c|c|c|c|c|c|c|c|c|c|}
\hline \multirow[t]{2}{*}{$\varepsilon_{\mathrm{r}}$} & \multicolumn{2}{|c|}{$\mathrm{NH}_{3}$ s str } & \multicolumn{2}{|c|}{$\mathrm{H}_{\mathrm{b}} \mathrm{str}$} & \multicolumn{2}{|c|}{$\mathrm{NH}_{3} \mathrm{umb}$} & \multicolumn{2}{|c|}{ Di str } & \multirow[t]{2}{*}{$\sum A i$} \\
\hline & $\nu 2$ & $A 1$ & $\nu 2$ & $A 2$ & $\nu 3$ & $A 3$ & $\nu 4$ & $A 4$ & \\
\hline 1.000 & $3480^{a}$ & $5^{a}$ & $1665^{b}$ & $2520^{b}$ & $1135^{c}$ & $44^{c}$ & 188 & 63 & 2631 \\
\hline 1.100 & 3480 & 6 & 1588 & 2788 & 1144 & 29 & 188 & 78 & 2901 \\
\hline 1.200 & 3478 & 7 & 1494 & 3074 & 1153 & 9 & 188 & 100 & 3190 \\
\hline 1.240 & 3478 & 7 & 1453 & 3190 & 1155 & 2 & 188 & 112 & 3311 \\
\hline 1.300 & 3474 & 8 & 1375 & 3352 & 1157 & 12 & 186 & 138 & 3510 \\
\hline 1.350 & 3477 & 9 & 1308 & 3361 & 1153 & 141 & 184 & 168 & 3511 \\
\hline 1.400 & 3473 & 10 & 1242 & 2439 & 1122 & 1221 & 177 & 219 & 3889 \\
\hline 1.420 & 3475 & 10 & 1084 & 2031 & 1235 & 1672 & 173 & 255 & 3989 \\
\hline 1.450 & 3475 & 11 & 992 & 2876 & 1214 & 930 & 161 & 348 & 4165 \\
\hline 1.460 & 3474 & 12 & 939 & 3063 & 1215 & 754 & 150 & 414 & 4243 \\
\hline 1.465 & 3475 & 12 & 905 & 3134 & 1214 & 681 & 141 & 466 & 4292 \\
\hline 1.470 & 3473 & 12 & 873 & 3179 & 1215 & 628 & 132 & 521 & 4340 \\
\hline 1.472 & 3473 & 12 & 855 & 3194 & 1216 & 604 & 126 & 555 & 4366 \\
\hline 1.475 & 3467 & 17 & 585 & 3019 & 1244 & 459 & 150 & 1505 & 5000 \\
\hline 1.480 & 3466 & 17 & 588 & 3211 & 1249 & 468 & 199 & 1358 & 5054 \\
\hline 1.500 & 3464 & 18 & 599 & 3707 & 1260 & 493 & 278 & 941 & 5159 \\
\hline 1.520 & 3463 & 19 & 604 & 4055 & 1267 & 512 & 318 & 631 & 5217 \\
\hline 1.550 & 3462 & 20 & 610 & 4448 & 1277 & 538 & 353 & 267 & 5272 \\
\hline 1.600 & 3460 & 22 & 640 & 4713 & 1291 & 584 & 377 & 2 & 5321 \\
\hline 1.630 & 3458 & 23 & 671 & 4662 & 1298 & 619 & 377 & 31 & 5334 \\
\hline 1.650 & 3458 & 23 & 697 & 4593 & 1303 & 645 & 374 & 76 & 5338 \\
\hline 1.700 & 3456 & 25 & 772 & 4411 & 1315 & 729 & 363 & 172 & 5337 \\
\hline 1.800 & 3452 & 28 & 929 & 4068 & 1338 & 995 & 346 & 216 & 5307 \\
\hline 1.900 & 3452 & 30 & 1062 & 3559 & 1361 & 1478 & 340 & 198 & 5265 \\
\hline 2.000 & 3451 & 32 & 1157 & 2797 & 1389 & 2216 & 338 & 183 & 5229 \\
\hline 2.200 & 3448 & 36 & 1468 & 3902 & 1264 & 1047 & 333 & 168 & 5154 \\
\hline 2.500 & 3446 & 42 & 1598 & 4664 & 1320 & 174 & 322 & 167 & 5047 \\
\hline 3.000 & 3443 & 51 & 1761 & 4631 & 1355 & 8 & 294 & 181 & 4872 \\
\hline 5.000 & 3434 & 83 & 2198 & 3832 & 1414 & 54 & 201 & 189 & 4158 \\
\hline 7.000 & 3428 & 110 & 2454 & 3186 & 1442 & 105 & 129 & 183 & 3584 \\
\hline
\end{tabular}

${ }^{a}$ For $\mathrm{NH}_{3}$ monomer calculated frequency (m.c.f.) $-3462 \mathrm{~cm}^{-1}$, intensity (int.) $-1 \mathrm{~km} / \mathrm{mol}$; for $\mathrm{NH}_{4}^{+}$m.c.f. $-3495 \mathrm{~cm}^{-1}$, int. $-593 \mathrm{~km} / \mathrm{mol}$. ${ }^{b}$ For BrH m.c.f. $-2563 \mathrm{~cm}^{-1}$, int. $-4 \mathrm{~km} / \mathrm{mol} .{ }^{c}$ For $\mathrm{NH}_{3}$ m.c.f. $-1090 \mathrm{~cm}^{-1}$, int. $-145 \mathrm{~km} / \mathrm{mol}$; for $\mathrm{NH}_{4}^{+}$m.c.f. $-1496 \mathrm{~cm}^{-1}$, int. $-543 \mathrm{~km} / \mathrm{mol}$. 


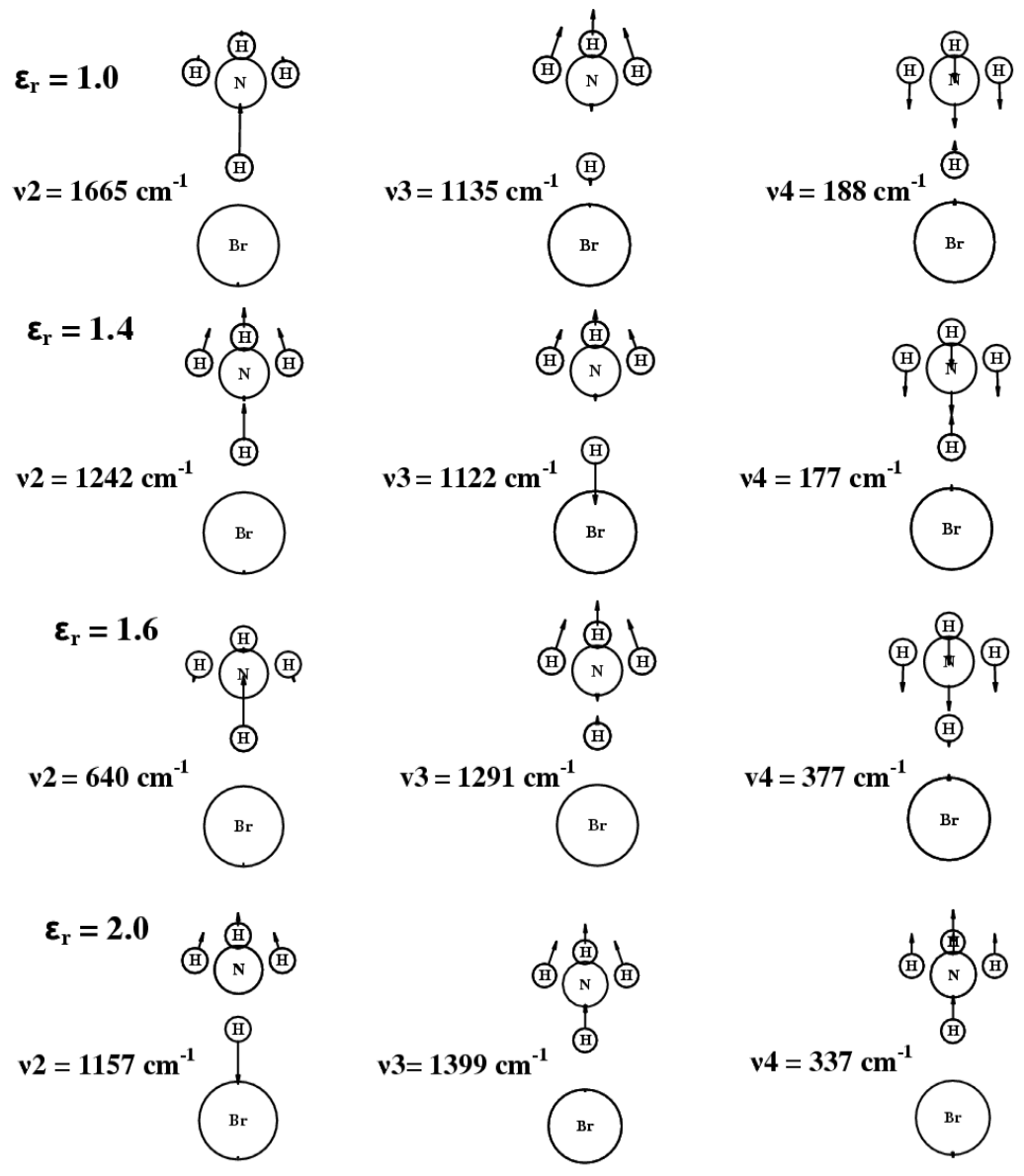

Fig. 4. Calculated displacement of atoms in normal modes $\nu 2, \nu 3$, and $\nu 4$ of the $\mathrm{BrH}: \mathrm{NH}_{3}$ complex in different dielectric fields characterized by $\varepsilon_{\mathrm{r}}$. These displacements were drawn using the Animol program (see [8] for details) to analyze the data from Gaussian 98 output.

For $\varepsilon_{\mathrm{r}}=1.4, \nu 2$ and $\nu 3$ are no longer pure proton stretch and $\mathrm{NH}_{3}$ umbrella bend, respectively, as they were for $\varepsilon_{\mathrm{r}}=1$ (shown also in Fig. 4). Instead, $\nu 2$ and $\nu 3$ both have large contributions from each of these two symmetry coordinates. An interaction between $\nu 2$ and $\nu 4$ (Di str) is apparent also for $\varepsilon_{\mathrm{r}}$ around 1.475, where a strong increase in the intensity of $\nu 4$ is observed. This interaction appears to be related to the "two-dimensional" coupling considered in [1]. The interaction involving $\nu 2$ and $\nu 4$ is complicated by the proton transfer reaction from the normal-molecule structure to the ion-pair structure that occurs for $\varepsilon_{\mathrm{r}}$ from 1.472 to 1.475 , discussed in Sect. 2.1.

For $\varepsilon_{\mathrm{r}}$ greater than 1.6 the frequency of $\nu 2$ increases and its intensity decreases (reaching a minimum for $\varepsilon_{\mathrm{r}}=2.0$ ) shown in Fig. 3. In contrast, the 
intensity of $\nu 3$ increases in this region of $\varepsilon_{\mathrm{r}}$ to a maximum at $\varepsilon_{\mathrm{r}}=2.0$ without very strong change in frequency. Again, these changes indicate that the interaction has changed the character of the normal modes.

This change of character of the mixing of the internal coordinates can be seen in Fig. 4 for $\varepsilon_{\mathrm{r}}=2.0$ and 1.6. As seen there, the character of $\nu 2$ is again pure proton stretch, and $\nu 3$ is pure $\mathrm{NH}_{3}$ umbrella bend for $\varepsilon_{\mathrm{r}}=1.60$. Greater mixing of the symmetry coordinates for each normal mode occurs for $\varepsilon_{\mathrm{r}}=2.0$, rather similar to the mixing shown at $\varepsilon_{\mathrm{r}}=1.4$ (see Fig. 4). Let us note that the complex is in the ion-pair form for $\varepsilon_{\mathrm{r}}>1.60$.

As seen in Fig. 4, the character of $\nu 4$ (Di str) also changes for each value of $\varepsilon_{\mathrm{r}}$, and has mixed contributions from the internal displacement coordinates for all.

It is worthwhile to note in Fig. 3 (left) that the total intensity of all four modes (marked by open circles) changes rather smoothly in this range of $\varepsilon_{\mathrm{r}}$, in contrast with the ups and downs of the individual intensities $(A 2, A 3$, and $A 4)$.

\subsubsection{Normal modes of e symmetry}

Table III lists the frequencies of the $e$ normal modes $(\nu 5, \nu 6, \nu 7$, and $\nu 8)$ of the $\mathrm{BrH}_{\mathrm{b}}: \mathrm{NH}_{3}$ complex in different dielectric fields. Each row in Table III lists values for all 4 normal modes from the SCRF calculation for the Onsager dielectric field characterized by the value of $\varepsilon_{\mathrm{r}}$ given in the first column. The frequencies and intensities of each normal mode are listed in alternating columns across the table.

It is clear from Table III that only the frequency $\nu 7$ of the perpendicular bending motion $\left(\mathrm{BrH}_{\mathrm{b}} \mathrm{N}\right.$ bend) is sensitive to changes of $\varepsilon_{\mathrm{r}}$, as illustrated in Fig. 5 . Before the transition from the normal-molecule structure to the ion-pair structure, the frequency of this mode increases from a value of $889 \mathrm{~cm}^{-1}$ (at $\left.\varepsilon_{\mathrm{r}}=1.0\right)$ to $1089 \mathrm{~cm}^{-1}$ (at $\left.\varepsilon_{\mathrm{r}}=1.472\right)$. After transition to the ion-pair structure $\left(\varepsilon_{\mathrm{r}}\right.$ changes from 1.472 to 1.475 ), the frequency of this motion increases from $1089 \mathrm{~cm}^{-1}$ to $1211 \mathrm{~cm}^{-1}$, and then continues to increase smoothly with increasing value of $\varepsilon_{\mathrm{r}}$ to $1503 \mathrm{~cm}^{-1}$ at $\varepsilon_{\mathrm{r}}=7.0$.

The infrared intensities of the absorption by these degenerate normal modes are each much lower than the intensity of $\nu 2$ mode (P str) in Table II. The biggest intensity change occurs for the $\mathrm{NH}_{3}$ as $\operatorname{str} \nu 5$ (from $32 \mathrm{~km} \mathrm{~mol}^{-1}$ for $\varepsilon_{\mathrm{r}}=1.0$ to $302 \mathrm{~km} \mathrm{~mol}^{-1}$ for $\varepsilon_{\mathrm{r}}=7.0$ ). The total intensity of absorption by all class $e$ normal modes shown in the last column of Table III ranges from only $210 \mathrm{~km} \mathrm{~mol}^{-1}$ (at $\varepsilon_{\mathrm{r}}=1.0$ ) to $558 \mathrm{~km} \mathrm{~mol}^{-1}$ (at $\varepsilon_{\mathrm{r}}=7.0$ ), compared with a range of 2631 to $5338 \mathrm{~km} \mathrm{~mol}^{-1}$ for the total intensity of all class $a_{1}$ modes, as shown in the last column of Table II.

The $e$ modes are much less sensitive to the environment than are the $a_{1}$ modes and because there is no interaction of normal modes between the two symmetry classes, there is no enhancement of intensity of an $e$ mode at the expense of the intensity of a nearby $a_{1}$ mode. The anharmonicity effect for $e$ symmetry 
TABLE III

Calculated frequencies $-\nu i-$ in $\left[\mathrm{cm}^{-1}\right]$ and intensities $-A i-$ in $[\mathrm{km} / \mathrm{mol}]$ of double degenerate $e$ normal modes of $\mathrm{BrH}_{\mathrm{b}}: \mathrm{NH}_{3}$ complex in different dielectric field characterized by relative permittivity $\varepsilon_{\mathrm{r}}$.

\begin{tabular}{|c|c|c|c|c|c|c|c|c|c|}
\hline \multirow[t]{2}{*}{$\varepsilon_{\mathrm{r}}$} & \multicolumn{2}{|c|}{$\mathrm{NH}_{3}$ as str } & \multicolumn{2}{|c|}{$\mathrm{NH}_{3}$ as def } & \multicolumn{2}{|c|}{$\mathrm{BrH}_{\mathrm{b}} \mathrm{N}$ be } & \multicolumn{2}{|c|}{$\mathrm{NH}_{3}$ rock } & \multirow[t]{2}{*}{$\sum A i$} \\
\hline & $\nu 5$ & $A 5$ & $\nu 6$ & $A 6$ & $\nu 7$ & $A 7$ & $\nu 8$ & $A 8$ & \\
\hline 1.000 & $3618^{a}$ & $32^{a}$ & $1674^{b}$ & $50^{b}$ & 889 & 88 & 261 & 39 & 211 \\
\hline 1.100 & 3617 & 37 & 1674 & 52 & 916 & 89 & 270 & 38 & 216 \\
\hline 1.200 & 3614 & 41 & 1674 & 55 & 946 & 89 & 278 & 37 & 222 \\
\hline 1.240 & 3614 & 43 & 1674 & 55 & 959 & 89 & 280 & 36 & 223 \\
\hline 1.300 & 3610 & 47 & 1673 & 57 & 981 & 89 & 290 & 35 & 228 \\
\hline 1.350 & 3612 & 50 & 1672 & 58 & 1000 & 90 & 290 & 34 & 232 \\
\hline 1.400 & 3608 & 54 & 1672 & 59 & 1024 & 89 & 299 & 33 & 236 \\
\hline 1.420 & 3610 & 56 & 1671 & 60 & 1036 & 90 & 297 & 32 & 238 \\
\hline 1.450 & 3611 & 61 & 1671 & 61 & 1059 & 89 & 300 & 31 & 241 \\
\hline 1.460 & 3609 & 62 & 1671 & 61 & 1070 & 89 & 304 & 31 & 243 \\
\hline 1.465 & 3610 & 64 & 1670 & 61 & 1078 & 89 & 304 & 31 & 244 \\
\hline 1.466 & 3609 & 64 & 1670 & 61 & 1078 & 89 & 306 & 31 & 244 \\
\hline 1.467 & 3609 & 64 & 1670 & 61 & 1080 & 89 & 306 & 31 & 244 \\
\hline 1.468 & 3609 & 64 & 1670 & 61 & 1082 & 89 & 306 & 31 & 245 \\
\hline 1.470 & 3609 & 65 & 1670 & 61 & 1085 & 89 & 307 & 30 & 245 \\
\hline 1.472 & 3608 & 65 & 1670 & 61 & 1089 & 89 & 308 & 30 & 246 \\
\hline 1.475 & 3603 & 89 & 1667 & 63 & 1211 & 89 & 324 & 24 & 265 \\
\hline 1.480 & 3602 & 92 & 1667 & 63 & 1223 & 89 & 324 & 24 & 268 \\
\hline 1.500 & 3600 & 99 & 1667 & 63 & 1250 & 91 & 324 & 21 & 275 \\
\hline 1.520 & 3598 & 104 & 1666 & 63 & 1267 & 92 & 323 & 20 & 280 \\
\hline 1.550 & 3596 & 110 & 1667 & 63 & 1287 & 94 & 323 & 19 & 287 \\
\hline 1.600 & 3593 & 119 & 1667 & 63 & 1314 & 97 & 323 & 18 & 296 \\
\hline 1.630 & 3591 & 124 & 1667 & 62 & 1327 & 99 & 324 & 17 & 301 \\
\hline 1.650 & 3590 & 127 & 1668 & 62 & 1336 & 100 & 324 & 17 & 305 \\
\hline 1.700 & 3588 & 133 & 1668 & 61 & 1354 & 103 & 325 & 16 & 313 \\
\hline 1.800 & 3582 & 145 & 1670 & 58 & 1381 & 109 & 329 & 15 & 326 \\
\hline 1.900 & 3580 & 154 & 1672 & 56 & 1399 & 114 & 328 & 14 & 338 \\
\hline 2.000 & 3577 & 161 & 1673 & 55 & 1412 & 119 & 328 & 13 & 348 \\
\hline 2.200 & 3573 & 174 & 1676 & 52 & 1429 & 128 & 328 & 12 & 365 \\
\hline 2.500 & 3567 & 188 & 1680 & 48 & 1446 & 139 & 330 & 11 & 386 \\
\hline 3.000 & 3559 & 208 & 1686 & 43 & 1465 & 154 & 333 & 10 & 415 \\
\hline 5.000 & 3539 & 264 & 1704 & 28 & 1495 & 199 & 340 & 7 & 499 \\
\hline 7.000 & 3525 & 302 & 1714 & 22 & 1503 & 228 & 340 & 6 & 558 \\
\hline
\end{tabular}

${ }^{a}$ For $\mathrm{NH}_{3}$ m.c.f. $-3591 \mathrm{~cm}^{-1}$, int. $-1 \mathrm{~km} / \mathrm{mol} .{ }^{b}$ For $\mathrm{NH}_{3}$ m.c.f. $1694 \mathrm{~cm}^{-1}$, int. $-27 \mathrm{~km} / \mathrm{mol}$. 


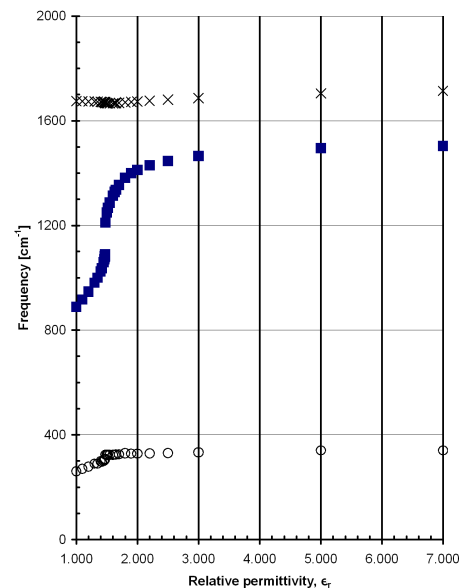

Fig. 5. Correlation with $\varepsilon_{\mathrm{r}}$ : calculated frequencies of the normal modes of $e$ symmetry $\nu 6-\operatorname{crosses} ; \nu 7-$ filled squares; and $\nu 8-$ circles.

modes is also expected to be much smaller than that for the $a_{1}$ mode $\nu 2$ discussed in Sect. 2.3.

\subsection{Effect of anharmonicity}

Results from calculations described above of the frequencies and intensities are subject to systematic errors, including the harmonic approximation. Hence, both calculated frequencies and intensities are expected to differ in value from those observed experimentally.

The most important effect of anharmonicity arises from the change in shape of the potential energy surface. The cross-section ("path") of the multidimensional energy surface followed by the $\mathrm{H}_{\mathrm{b}}$ stretching coordinate is called the potential energy curve for the internal coordinate in the following text. These potential energy curves are computed at the DFT B3LYP $\backslash 6-31 G(d, p)$ SCRF level using the partial optimization method described in [13]. In this point-by-point calculation a constrained-geometry optimization (so-called relaxed scan) is performed at each value of the $R\left(\mathrm{BrH}_{\mathrm{b}}\right)$ distance to obtain the energy and geometry for the complex at the stationary point for this distance.

Figure 6 shows the relaxed energy curves of the complex obtained in this manner as a function of $R\left(\mathrm{BrH}_{\mathrm{b}}\right)$ for several $\varepsilon_{\mathrm{r}}$ values. The upper curve (marked by triangular points) in Fig. 6 shows this potential for the complex at $\varepsilon_{\mathrm{r}}=1.0$ (in vacuum). The other curves show how this potential changes in dielectric fields corresponding to $\varepsilon_{\mathrm{r}}=1.24,1.47,1.6,2.2$, and 3.0 .

As seen in Fig. 6, the equilibrium structure in vacuum is the neutral molecule complex $\left(\mathrm{Br}-\mathrm{H}_{\mathrm{b}}: \mathrm{NH}_{3}\right)$ with $R\left(\mathrm{BrH}_{\mathrm{b}}\right)=1.511 \AA$. A vague shoulder appearing above the minimum (on the right side) hints at the contribution of the ion-pair structure $\left(\mathrm{Br}^{-}: \mathrm{H}_{\mathrm{b}} \mathrm{NH}_{3}^{+}\right)$. At $\varepsilon_{\mathrm{r}}=1.24$ (close to that of solid $\mathrm{Ne}$ ) the equilibrium 


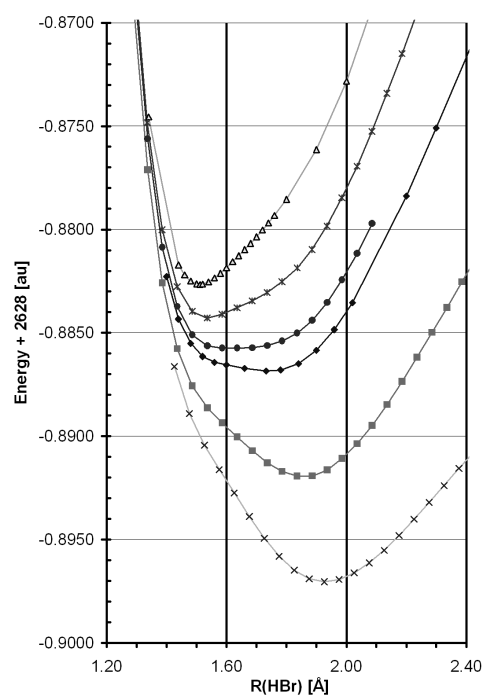

Fig. 6. Calculated relaxed energy curves as a function of $\mathrm{BrH}$ distance of the $\mathrm{BrH}: \mathrm{NH}_{3}$ complex in dielectric field characterized by $\varepsilon_{\mathrm{r}}$ - for $\varepsilon_{\mathrm{r}}=1.00$ - triangles; $\varepsilon_{\mathrm{r}}=1.24$ stars; $\varepsilon_{\mathrm{r}}=1.47$ - filled circles; $\varepsilon_{\mathrm{r}}=1.60$ - filled diamonds; $\varepsilon_{\mathrm{r}}=2.20$ - filled squares; $\varepsilon_{\mathrm{r}}=3.00-$ crosses.

structure with $R\left(\mathrm{BrH}_{\mathrm{b}}\right)=1.535 \AA$ is still the neutral molecule complex but the difference between the minimum energy and shoulder is smaller.

For $\varepsilon_{\mathrm{r}}=1.47$ (near the transition point to the ion-pair form) and for $\varepsilon_{\mathrm{r}}=1.6$ (close to solid Ar) the energy curve exhibits an almost flat broad minimum for the ion-pair merging into vague shoulder (more visible for $\varepsilon_{\mathrm{r}}=1.6$ ) related to the neutral-molecule complex (on the left side). For the field related to $\varepsilon_{\mathrm{r}}=2.20$ the ionic form (with $R_{\mathrm{e}}\left(\mathrm{BrH}_{\mathrm{b}}\right)=1.836 \AA$ ) is more stable than the neutral-molecule complex related to the shoulder on the left side. The lowest energy curve in Fig. 6 corresponds to $\varepsilon_{\mathrm{r}}=3.00$, and shows that the ion-pair form (with $R_{\mathrm{e}}\left(\mathrm{BrH}_{\mathrm{b}}\right)=$ $1.926 \AA$ ) has much lower energy than the neutral molecule corresponding to the shoulder (on the left side). These results show that the nature of the hydrogen bond between $\mathrm{BrH}_{\mathrm{b}}$ and $\mathrm{NH}_{3}$ does indeed depend on the dielectric environment.

The energy curves shown in Fig. 6 clearly differ in shape from those for a harmonic potential. This difference is emphasized in Fig. 7 for $\varepsilon_{\mathrm{r}}=1.24$ (left) and 1.6 (right). In Fig. 7 the energy is expressed as the difference from equilibrium $\left(E-E_{\mathrm{e}}\right.$ in $\left.\mathrm{cm}^{-1}\right)$ as a function of the mass-weighted displacement coordinate $q(\mathrm{BrH}) \approx\left[R(\mathrm{BrH})-R_{\mathrm{e}}(\mathrm{BrH})\right] \times(\text { reduced mass })^{1 / 2}$. These plots show the potential energy function for the proton stretch, on the assumption that the displacement coordinate is indeed pure proton stretch as defined in Sect. 2.2.1.

The shape of the potential energy function for $\nu 2$ has changed from the parabola $2 V\left(q_{2}\right)=k\left(q_{2}\right)^{2}$ to a broader asymmetric curve that is fit better by a one-dimensional quartic function $V\left(q_{2}\right)=a\left(q_{2}\right)^{4}+b\left(q_{2}\right)^{3}+c\left(q_{2}\right)^{2}+d\left(q_{2}\right)$. The solution 


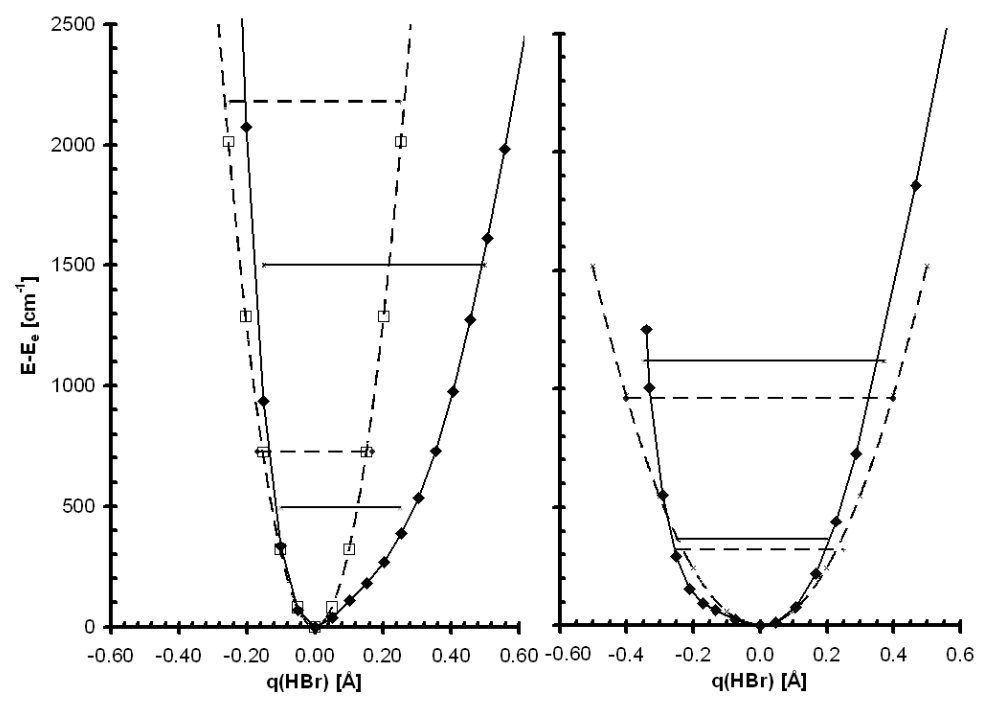

Fig. 7. Comparison of the calculated harmonic (- - ) and anharmonic relaxed potential (filled diamonds and solid line) energy curves for the $\mathrm{BrH}: \mathrm{NH}_{3}$ complex in a dielectric field: left - for $\varepsilon_{\mathrm{r}}=1.24$; right - for $\varepsilon_{\mathrm{r}}=1.60$. Horizontal bars show vibrational energy levels $E(v=0)$ and $E(v=1)$ for harmonic (- - ) and anharmonic (-) potentials.

$[8,10]$ of the one-dimensional time-independent Schrödinger equation using this relaxed potential in the Somorjai-Hornig perturbation procedure [14] leads to the value of the anharmonic frequency $\nu_{\mathrm{anh}}$ (P str) for the transition from the $v=0$ to the $v=1$ vibrational level.

In Fig. 7 solid horizontal lines correspond to $v=0$ and $v=1$ levels for $\nu_{\text {anh }}(\mathrm{P}$ str) are compared with the corresponding states (dashed horizontal lines) for the harmonic potential. As seen in this figure the difference between the anharmonic and harmonic potentials and energy level spacing is much larger for $\varepsilon_{\mathrm{r}}=1.24$ (left figure). This contrasts with observation of the right figure $\left(\varepsilon_{\mathrm{r}}=1.6\right)$ where the harmonic and anharmonic potentials are very similar, and the corresponding energy levels are quite similar. This comparison implies that the frequency of the proton stretch from the harmonic calculation for $\varepsilon_{\mathrm{r}}=1.6$ may not be very different from the experimental (anharmonic) frequency in the Ar matrix $\left(\varepsilon_{\mathrm{r}}\right.$ around $1.61-1.63)$.

Table IV summarizes values of the anharmonic frequencies and $R_{0}\left(\mathrm{BrH}_{\mathrm{b}}\right)$ obtained using this procedure for the $\mathrm{BrH}_{\mathrm{b}}: \mathrm{NH}_{3}$ complex in fields with $\varepsilon_{\mathrm{r}}=1.0$, $1.24,1.6,1.8$, and 2.2. It is important to notice that the magnitude of the correction for this anharmonicity effect decreases from about $500 \mathrm{~cm}^{-1}$ for $\varepsilon_{\mathrm{r}}=1.00$ to about $100-200 \mathrm{~cm}^{-1}$ for $\varepsilon_{\mathrm{r}}=1.6-1.8$, and then increases again to about $500 \mathrm{~cm}^{-1}$ for $\varepsilon_{\mathrm{r}}=2.2$.

Because the fit of the fourth-order polynomial to the calculated relaxed potential energy curve is not precise, the estimated value of the anharmonic frequency 
TABLE IV

Comparison of the calculated harmonic, $\nu($ ha) and anharmonic $\nu$ (anh) frequencies and $\mathrm{BrH}$ distances at equilibrium $R_{\mathrm{e}}(\mathrm{BrH})$ and $R_{0}(\mathrm{BrH})$ in the $\nu=0$ state.

\begin{tabular}{c|c|c|c|c|c|c}
\hline \hline$\varepsilon_{\mathrm{r}}$ & $\begin{array}{c}\nu(\mathrm{ha}) \\
{\left[\mathrm{cm}^{-1}\right]}\end{array}$ & $\begin{array}{c}\nu(\mathrm{anh}) \\
{\left[\mathrm{cm}^{-1}\right]}\end{array}$ & $\begin{array}{c}\nu(\mathrm{ha})-\nu(\mathrm{anh}) \\
{\left[\mathrm{cm}^{-1}\right]}\end{array}$ & $\begin{array}{c}R_{\mathrm{e}}(\mathrm{BrH}) \\
{[\AA]}\end{array}$ & $\begin{array}{c}R_{0}(\mathrm{BrH}) \\
{[\AA]}\end{array}$ & $\begin{array}{c}R_{\mathrm{e}}-R_{0} \\
{[\AA]}\end{array}$ \\
\hline 1 & 1665 & 1127 & 536 & 1.511 & 1.582 & -0.071 \\
1.24 & 1453 & 1009 & 444 & 1.535 & 1.638 & -0.103 \\
1.6 & 640 & 750 & -110 & 1.732 & 1.707 & 0.025 \\
1.8 & 929 & 700 & 229 & 1.795 & 1.758 & 0.037 \\
2.2 & 1468 & 967 & 521 & 1.857 & 1.841 & 0.016
\end{tabular}

has an uncertainty on the order of $100 \mathrm{~cm}^{-1}$. The error from the assumption that the normal coordinate $q_{2}$ is approximately equal to the mass-weighted internal displacement coordinate might possibly be much larger.

\section{Comparison of calculated and experimental spectra}

The most complete experimental spectra, including both frequencies and intensities, that are available to us for the isolated $\mathrm{BrH}: \mathrm{NH}_{3}$ complex are those obtained in our laboratory for the complex in solid $\mathrm{Ar}$ and in solid $\mathrm{N}_{2}$ matrices. Infrared spectra were measured with a Nicolet Model 740 FTIR spectrometer sensitive down to $450 \mathrm{~cm}^{-1}$. Solid ammonium bromide (from Aldrich) was sublimed into a stream on matrix gas and the mixture was condensed onto the CsI window mounted on the cold (about $10 \mathrm{~K}$ ) finger of the cryostat (closed cycle helium cryostat - Displex Model DE-202 from APD Cryogenics, Inc.). Details of the experimental setup and methods of measuring integrated intensities (areas under band contours) as well as those for the analysis of the spectra using Grams, Animol, and Xtrapack programs were described in the earlier papers cited $[6-10,15]$.

\subsection{Spectra in argon matrix}

The experimental spectrum of an argon matrix at about $10 \mathrm{~K}$ containing $\mathrm{BrH}$ and $\mathrm{NH}_{3}$ is shown in Fig. 8. The top trace shows the spectrum of a dilute matrix with the ratio of $\mathrm{Ar}: \mathrm{BrH}: \mathrm{NH}_{3}$ about $1000: 1: 1$. This spectrum is dominated by the known absorption bands of rotating monomers of $\mathrm{NH}_{3}$ near $974 \mathrm{~cm}^{-1}$. Other weaker bands of $\mathrm{NH}_{3}$ monomers are visible near 1638 and $3447 \mathrm{~cm}^{-1}$. The absorption by monomers of $\mathrm{BrH}$ is very weak and appears near $2568 \mathrm{~cm}^{-1}$. Other absorption bands appear at 729,592 , and $1147 \mathrm{~cm}^{-1}$. The absorbance of these last three bands increases strongly relative to that of monomers in a spectrum of a matrix with higher concentrations of $\mathrm{NH}_{3}$ and $\mathrm{HBr}$ shown in the middle trace of Fig. 8, indicating that they are related to the $\mathrm{BrH}_{\mathrm{b}}: \mathrm{NH}_{3}$ complex (most likely, one-to-one). 


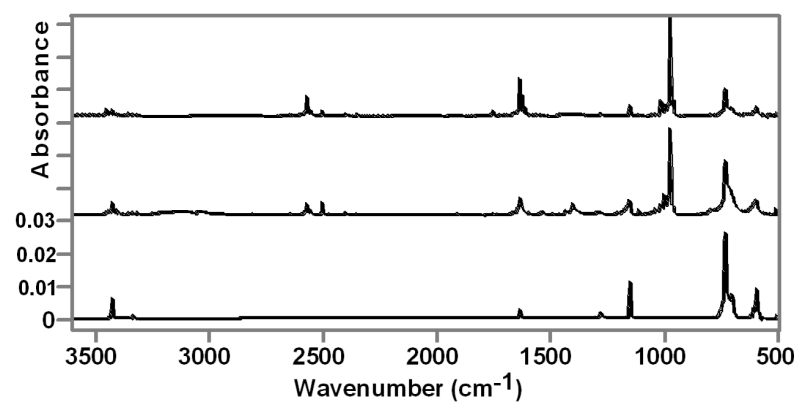

Fig. 8. Experimental infrared spectra of a mixture of $\mathrm{BrH}$ and $\mathrm{NH}_{3}$ in an Ar matrix at about $10 \mathrm{~K}$. Top trace - lower concentration of $\mathrm{BrH}$ and $\mathrm{NH}_{3}$; middle trace - higher concentration of $\mathrm{BrH}$ and $\mathrm{NH}_{3}$. Bottom trace - spectrum of the one to one $\mathrm{BrH}: \mathrm{NH}_{3}$ complex.

Closer examination of the spectra at expanded scales of the top and middle traces in Fig. 8, reveals other weak bands (at 3420, 1630, and $1275 \mathrm{~cm}^{-1}$ ) that may be related to the $1: 1 \mathrm{BrH}: \mathrm{NH}_{3}$ complex. The frequencies of these bands are distinctly different from the well known frequencies of dimers and higher aggregates of $\mathrm{NH}_{3}$ or of $\mathrm{BrH}$ in an Ar matrix (studied and assigned by several authors (e.g. $[16,17,5]$ and references therein)).

The spectrum at the bottom of Fig. 8, we believe, is the spectrum of the 1:1 $\mathrm{BrH}: \mathrm{NH}_{3}$ complex in the region from 3500 to $500 \mathrm{~cm}^{-1}$. This spectrum was obtained from the top trace by subtracting the absorption of $\mathrm{BrH}$ and $\mathrm{NH}_{3}$ monomers and that related to traces of their aggregates. The region $\left(1300-500 \mathrm{~cm}^{-1}\right)$ containing the most intense bands is shown in Fig. 9. The relative integrated absorption intensities are given in brackets next to the marked frequencies.

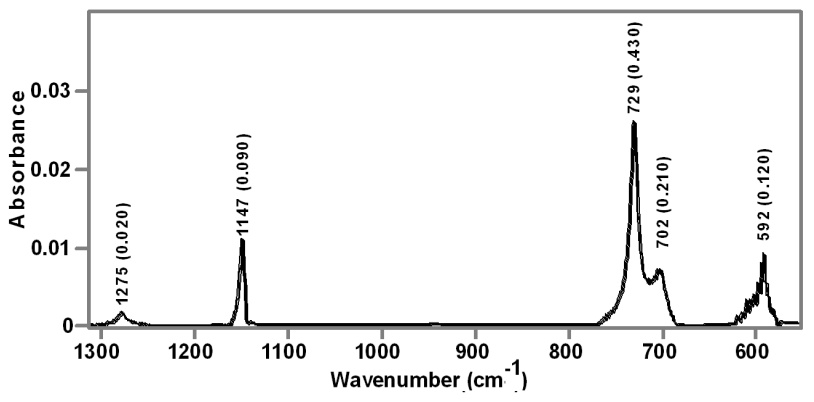

Fig. 9. Region $1300-500 \mathrm{~cm}^{-1}$ of the spectrum of the complex (from the bottom trace in Fig. 8) showing the components of the triplet near $700-600 \mathrm{~cm}^{-1}$ (with marked frequency and integrated absorbance).

Table V compares the experimental frequencies and absorption intensities with the calculated data from the preceding Sect. 2, for the $\mathrm{BrH}: \mathrm{NH}_{3}$ complex in 
TABLE V

Comparison of the calculated frequencies $(\nu($ ha $)$ and $\nu(\operatorname{anh}))$ and intensities ( $A$ and $A / A(\nu 2)$ ) for the $\mathrm{BrH}_{\mathrm{b}}: \mathrm{NH}_{3}$ complex in the dielectric field $\left(\varepsilon_{\mathrm{r}}=1.6\right.$ ) with the experimental frequencies $\left(\nu_{\exp }\right)$ and intensities $\left(I_{\exp }\right.$ and $\left.I_{\exp } / I_{\Sigma}\right)$ for this complex isolated in an Ar matrix.

\begin{tabular}{|c|c|c|c|c|c|c|c|c|c|c|}
\hline \multicolumn{8}{|c|}{ Calculation } & \multicolumn{3}{|c|}{ Experiment } \\
\hline $\begin{array}{l}\text { Norm. } \\
\text { mode }\end{array}$ & $\begin{array}{l}\nu(\text { ha }) \\
{\left[\frac{1}{\mathrm{~cm}}\right]}\end{array}$ & $\begin{array}{c}\nu(\mathrm{anh}) \\
{\left[\frac{1}{\mathrm{~cm}}\right]}\end{array}$ & $\begin{array}{c}A \\
{\left[\frac{\mathrm{km}}{\mathrm{mol}}\right]}\end{array}$ & $\frac{A}{A(\nu 2)}$ & Sym coor & $\begin{array}{c}\text { PED } \\
{[\%]}\end{array}$ & $\begin{array}{c}\text { ID } \\
{\left[\frac{\mathrm{km}}{\mathrm{mol}}\right]}\end{array}$ & $\begin{array}{l}\nu_{\exp } \\
{\left[\frac{1}{\mathrm{~cm}}\right]}\end{array}$ & $\begin{array}{l}I_{\exp } \\
{\left[\frac{1}{\mathrm{~cm}}\right]}\end{array}$ & $\frac{I_{\exp }}{I_{\Sigma}}$ \\
\hline 1 & 2 & 3 & 4 & 5 & 6 & 7 & 8 & 9 & 10 & 11 \\
\hline$\nu 5$ & 3593 & $3449^{a}$ & 118 & 0.025 & $e \mathrm{NH}_{3}$ as $\mathrm{str}$ & 100 & 104 & 3444 & 0.016 & 0.020 \\
\hline$\nu 1$ & 3460 & $3342^{b}$ & 22 & 0.006 & $a_{1} \mathrm{NH}_{3}$ sy str & 100 & 20 & 3345 & 0.003 & 0.004 \\
\hline$\nu 6$ & 1667 & $1612^{c}$ & 63 & 0.013 & $\begin{array}{c}e \mathrm{NH}_{3} \text { as def } \\
e \mathrm{NH}_{3} \text { rock }\end{array}$ & $\begin{array}{c}95+ \\
4+\end{array}$ & $\begin{array}{c}86 \\
-28\end{array}$ & 1630 & 0.010 & 0.013 \\
\hline$\nu 7$ & 1314 & $1271^{c}$ & 97 & 0.02 & $\begin{array}{c}e \mathrm{BrH}_{\mathrm{b}} \mathrm{N} \text { be } \\
e \mathrm{NH}_{3} \text { rock } \\
e \mathrm{NH}_{3} \text { as def }\end{array}$ & $\begin{array}{c}56+ \\
39- \\
5-\end{array}$ & $\begin{array}{c}94 \\
-16 \\
20\end{array}$ & 1275 & 0.02 & 0.026 \\
\hline$\nu 3$ & 1291 & $1153^{d}$ & 585 & 0.125 & $\begin{array}{c}a_{1} \mathrm{NH}_{3} \text { umb } \\
a_{1} \mathrm{P} \text { str }\end{array}$ & $\begin{array}{l}97- \\
2-\end{array}$ & $\begin{array}{l}274 \\
317\end{array}$ & 1147 & 0.09 & 0.118 \\
\hline$\nu 2$ & 640 & $750^{e}$ & 4713 & 1 & $a_{1} \mathrm{P}$ str & $98-$ & 4811 & $\begin{array}{l}729 \\
702 \\
592\end{array}$ & $\begin{array}{c}0.430 \\
0.21 \\
0.12 \\
\Sigma 0.76\end{array}$ & 1 \\
\hline$\nu 4$ & 377 & $362^{a}$ & 3 & 0.0006 & $a_{1}$ Di str & $99+$ & 1 & $f$ & & \\
\hline$\nu 8$ & 325 & $312^{a}$ & 18 & 0.004 & $\begin{array}{l}e \mathrm{NH}_{3} \text { rock } \\
e \mathrm{BrH}_{\mathrm{b}} \mathrm{N} \text { be }\end{array}$ & $\begin{array}{l}60+ \\
40+\end{array}$ & $\begin{array}{c}4 \\
14 \\
\end{array}$ & $f$ & & \\
\hline
\end{tabular}

the dielectric field characterized by $\varepsilon_{\mathrm{r}}=1.6$ (close to that of solid $\operatorname{Ar}(1.63[18]$ or $\left.\left.1.61\left(=n^{2}\right)[19]\right)\right)$. The first eight columns on the left side of the table summarize the calculated data.

The normal modes $\nu 1-\nu 8$ are listed in column 1. Corresponding calculated harmonic frequencies (unscaled) are listed in column 2. Column 3 presents the related anharmonic frequencies of each mode obtained (with the exception of the proton stretch mode $\nu 2$ ) by multiplying the harmonic frequency by scaling factors given in the footnotes of Table $\mathrm{V}$. These factors are defined for each normal mode of the complex as equal to the ratio of $\nu_{\text {exp }} / \nu_{\text {cal }}($ ha) for the corresponding mode of $\mathrm{NH}_{3}$ monomer; $\nu_{\text {exp }}$ is the experimental frequency observed for $\mathrm{NH}_{3}$ isolated in Ar matrix and $\nu_{\text {cal }}($ ha) is the value calculated at the same level of theory for the monomer at $\varepsilon_{\mathrm{r}}=1$, listed in the footnotes in Tables II and III. The anharmonic frequency of the proton stretching mode $\nu 2$ is taken from Table IV.

Column 4 shows calculated intensities taken from Tables II and III. Once again we emphasize that the calculated intensity of the proton stretching mode $\nu 2$ is very much larger than that of any other mode. The next most intense mode, $\nu 3$, is 8 times weaker than $\nu 2$. The intensities of the other six fundamental modes are all calculated to be much smaller. In column 5 the ratios of the calculated intensities to that of $\nu 2$ are given for comparison with the experimentally measured relative intensities. 
Column 6 lists the internal symmetry coordinates that contribute to each normal mode. The percentage contribution from each to the potential energy distribution (PED; see [8] and references therein) is given in column 7 (signs + or - describe their phase in the vibration). The main contributions from each internal symmetry coordinate to the intensity of the normal mode (the intensity distribution or ID; see [8] and references therein) are given in column 8. It is interesting to note that the main contribution to the PED of $\nu 3(97 \%)$ comes from the $\mathrm{NH}_{3}$ umbrella bend symmetry coordinate with only $3 \%$ from the proton stretch (P str). However, the ID shows that more than half of the intensity of $\nu 3$ is from the proton stretch internal symmetry coordinate.

Finally we come to the experimental results presented on the right-hand side of Table V. The experimental frequencies for spectra shown in Figs. 8 and 9 are given in column 9 and the corresponding values of integrated absorbance $\left(I_{\exp }\right)$ are listed in column 10 .

Comparison of these experimental results (first for the frequencies in column 10 with the calculated values in column 3) immediately focuses our attention on one of the major discrepancies between the calculated data and the experimental spectrum; namely, there are three strong absorption bands in the experimental spectrum (at 729, 702, and $592 \mathrm{~cm}^{-1}$ ) and only one strong band in the calculated spectrum at $750 \mathrm{~cm}^{-1}$. Furthermore, there are no other calculated modes nearby.

We believe that the explanation for the appearance of these three strong bands in the experimental spectrum is the Fermi resonance between the very intense fundamental $\nu 2$ and the $a_{1}$ components of overtones of lower frequency modes. The low frequency region is inaccessible in our spectrometer, so we cannot measure experimental frequencies below $450 \mathrm{~cm}^{-1}$ to examine this hypothesis. Frequencies of overtones can be estimated from the calculated anharmonic frequencies for $\nu 4$ and $\nu 8$ (column 3 of Table V) to give $2 \cdot \nu 4=724$ and $2 \cdot \nu 8=630 \mathrm{~cm}^{-1}$. If these estimated values are even close to the true overtone frequencies, it seems very likely that the Fermi resonance involving $\nu 2,2 \cdot \nu 4$, and $2 \cdot \nu 8$ could be expected to occur to produce a triplet very similar to that observed in the experimental spectrum.

Earlier studies of the spectra of the $\mathrm{BrH}: \mathrm{NH}_{3}$ complex $[2,5]$ have suggested that the band at $592 \mathrm{~cm}^{-1}$ might be assigned to the $\mathrm{BrH}_{\mathrm{b}} \mathrm{N}$ bend $(\nu 7$ in Table $\mathrm{V})$. We do not think that this alternative assignment can be correct for the following reasons. First, the experimental frequency $\left(592 \mathrm{~cm}^{-1}\right)$ is drastically lower than the calculated frequency of this mode $\left(1314 \mathrm{~cm}^{-1}\right.$, see Table $\left.\mathrm{V}\right)$. The difference is much greater than is reasonable to expect for an error due the method of calculation or to some extra anharmonic correction for the $\mathrm{BrH}_{\mathrm{b}} \mathrm{N}$ bending vibration. Second, the experimental band at $592 \mathrm{~cm}^{-1}$ has relatively very high intensity. Its integrated absorbance $I_{\exp }$ in column 10 of Table $\mathrm{V}$ is only 3.6 times smaller than $I_{\exp }$ for the band at $729 \mathrm{~cm}^{-1}$. The calculated intensity for the $\mathrm{NH}_{\mathrm{b}} \mathrm{Br}$ bend is 48 times lower than the intensity of the $\nu 2$ mode. This discrepancy is much larger than 
the experimental error in measuring relative intensities or than the errors in the calculated intensity ratios.

If the triplet at 729,702 , and $592 \mathrm{~cm}^{-1}$ is indeed due to the Fermi resonance, then the sum of the intensity from all three bands is expected to be equal to the intensity of the proton stretch. The sum of integrated absorbance for these three components is 0.76 . Taking this value as a reference, the relative intensity of each experimental band is obtained and listed in column 11 of Table V. As can be seen in the table these values of experimental relative intensities are very close to the corresponding calculated relative intensities in column 5. Considering the simplicity of the calculation, we are astonished by the quality of this agreement.

\subsection{Other matrices and correlations}

Because the experimental intensities for $\mathrm{BrH}: \mathrm{NH}_{3}$ in solid Ne and $\mathrm{Kr}$ matrices are not given in earlier works $[17,5]$, experimental results for these matrices shall be discussed very briefly. The recent experimental studies [5] of the $\mathrm{BrH}$ : $\mathrm{NH}_{3}$ complex isolated in solid $\mathrm{Ne}\left(\varepsilon_{\mathrm{r}}=1.23\right.$ [19]) and solid $\mathrm{Kr}\left(\varepsilon_{\mathrm{r}}=1.82\right.$ [19]) observe absorption by the hydrogen bonded proton stretching mode $(\nu 2)$ at 1080 and $700 \mathrm{~cm}^{-1}$, respectively. Both these frequencies are not far from the anharmonic frequencies given in Sect. 2.3. For dielectric fields with $\varepsilon_{\mathrm{r}}=1.24$ and $\varepsilon_{\mathrm{r}}=1.80$, the anharmonic frequencies are $1009 \mathrm{~cm}^{-1}$ and $700 \mathrm{~cm}^{-1}$, respectively.

It is well known that $\mathrm{N}_{2}$ matrix has a larger effect on the infrared spectra of trapped molecules than $\mathrm{Ar}$ or $\mathrm{Kr}$ matrices [2], despite the fact that $\varepsilon_{\mathrm{r}}$ of solid $\mathrm{N}_{2}$ (1.43 [20]) is smaller than those for solid Ar or Kr. This suggests that the procedure described above for rare gas matrices might not be adequate to account for the effect of an $\mathrm{N}_{2}$ matrix on the $\mathrm{BrH}: \mathrm{NH}_{3}$ complex. Our exploration of this question is not yet complete, so we shall not say more here about our own experimental studies made for the $\mathrm{N}_{2}$ matrix, but just say that the very strong band assigned to the proton stretch is observed at $1392 \mathrm{~cm}^{-1}$, in agreement with others $[2,5]$.

Despite the agreement between calculation and experiment shown in the previous section we are aware that the cavity model is not perfect. However, we do believe that the correlations (between frequencies and distances, for example) based on data in Tables I-III could be valid and useful.

One such correlation between calculated values of $R\left(\mathrm{BrH}_{\mathrm{b}}\right)$ and proton stretch $\nu 2$ is shown in Fig. 10. An encouraging observation supporting the validity of this correlation is that experimentally known frequencies and $R(\mathrm{BrH})$ distances for $\mathrm{HBr}$ monomer [21] and for solid $\mathrm{NH}_{4} \mathrm{Br}[22,23]$ appear to fit the correlation. This last observation inspired us to include experimental frequencies of $\nu 2$ for different matrices on this correlation. These frequencies are marked by the four short horizontal bars crossing the correlation curve. The points where bars cross the correlation provide approximate values for the "experimental" $R\left(\mathrm{BrH}_{\mathrm{b}}\right)$ for the complex isolated in each matrix. A similar correlation between $\nu 2$ and $R\left(\mathrm{NH}_{\mathrm{b}}\right)$ can be made. 


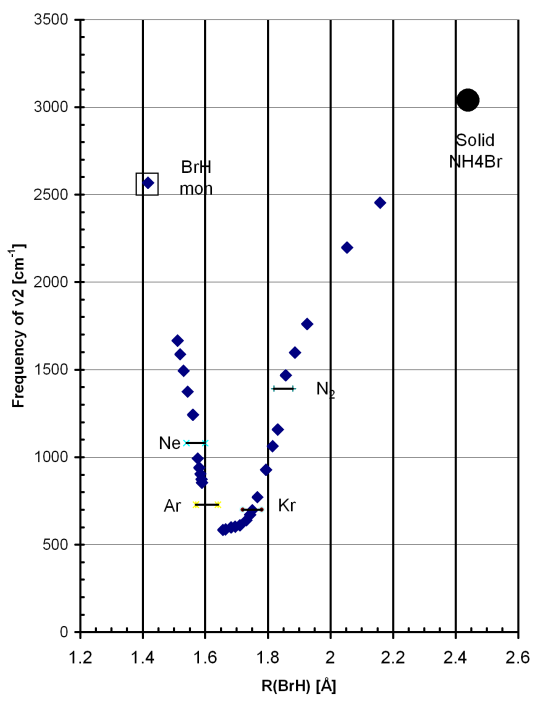

Fig. 10. Correlation between calculated harmonic frequencies of the proton stretching normal mode of the $\mathrm{BrH}: \mathrm{NH}_{3}$ complex with the $R(\mathrm{BrH})$ distance. Points marked by filled diamonds are data from Table I and II; the point marked by $\square$ is for the experimental data for gaseous $\mathrm{BrH}$; point marked by $\bullet$ corresponds to the experimental data for solid ammonium bromide; horizontal bars — mark the experimentally observed frequencies in $\mathrm{Ne}, \mathrm{Ar}, \mathrm{Kr}$, and $\mathrm{N}_{2}$ matrices.

We believe that these results suggest that it is possible to carry out reasonably simple calculations that can guide understanding and interpretation of experimental results.

\section{Acknowledgments}

We are very grateful to Pierre Chabrier for the development of the Xtrapack program, for measurement of the matrix spectra, and for his stimulating questions about the application of calculations to interpret infrared spectra.

\section{References}

[1] J.E. Del Bene, M.J.T. Jordan, P.M.W. Gill, A.D. Buckingham, Mol. Phys. 92, 429 (1997).

[2] A.J. Barnes, Z. Latajka, M. Biczysko, J. Mol. Struct. 614, 11 (2002).

[3] M.J.T. Jordan, J.E. Del Bene, J. Am. Chem. Soc. 122, 2101 (2000).

[4] A. Abkowicz-Bienko, M. Biczysko, Z. Latajka, Comput. Chem. 24, 303 (2000).

[5] L. Andrews, X. Wang, J. Phys. Chem. A 105, 6420 (2001).

[6] K. Szczepaniak, P. Chabrier, W.B. Person, J.E. Del Bene, J. Mol. Struct. 436437, 367 (1997).

[7] K. Szczepaniak, P. Chabrier, W.B. Person, J.E. Del Bene, J. Mol. Struct. 520, 1 (2000). 
[8] K. Szczepaniak, M.M. Szczesniak, W.B. Person, J. Phys. Chem. A 104, 3852 (2000).

[9] W.B. Person, K. Szczepaniak, J.S. Kwiatkowski, Int. J. Quant. Chem. 90, 995 (2002).

[10] K. Szczepaniak, W.B. Person, D. Hadzi, J. Phys. Chem. A 109, 6710 (2005).

[11] Gaussian 98, Revision A.9, M.J. Frisch, G.W. Trucks, H.B. Schlegel, G.E. Scuseria, M.A. Robb, J.R. Cheeseman, V.G. Zakrzewski, J.A. Montgomery, Jr., R.E. Stratmann, J.C. Burant, S. Dapprich, J.M. Millam, A.D. Daniels, K.N. Kudin, M.C. Strain, O. Farkas, J. Tomasi, V. Barone, M. Cossi, R. Cammi, B. Mennucci, C. Pomelli, C. Adamo, S. Clifford, J. Ochterski, G.A. Petersson, P.Y. Ayala, Q. Cui, K. Morokuma, D.K. Malick, A.D. Rabuck, K. Raghavachari, J.B. Foresman, J. Cioslowski, J.V. Ortiz, A.G. Baboul, B.B. Stefanov, G. Liu, A. Liashenko, P. Piskorz, I. Komaromi, R. Gomperts, R.L. Martin, D.J. Fox, T. Keith, M.A. Al-Laham, C.Y. Peng, A. Nanayakkara, M. Challacombe, P.M.W. Gill, B. Johnson, W. Chen, M.W. Wong, J.L. Andres, C. Gonzalez, M. Head-Gordon, E.S. Replogle, J.A. Pople, Gaussian, Inc., Pittsburgh PA, 1998.

[12] I. Mills, T. Cvitas, K. Homann, N. Kallay, K. Kuchitsu, Quantities, Units and Symbols in Physical Chemistry, 2nd ed., International Union of Pure and Applied Chemistry, Blackwell Science, Oxford 1993.

[13] A.E. Frisch, M.J. Frisch, Gaussian 98, User's Reference, 2nd ed., Gaussian Inc., Pittsburgh, PA 1999.

[14] R.I. Somorjai, D.F. Hornig, J. Chem. Phys. 36, 1980 (1962).

[15] P. Chabrier, Ph.D. Thesis, University of Florida, 1998.

[16] L. Abouaf-Marguin, M.E. Jacox, D.E. Milligan, J. Mol. Spectrosc. 67, 34 (1977).

[17] A.J. Barnes, M.P. Wright, J. Chem. Soc., Faraday Trans. 2 82, 153 (1986).

[18] H.E. Hallam, G.F. Scrimshaw, in: Vibrational Spectroscopy of Trapped Species, Ed. H.E. Hallam, Wiley, New York 1973, p. 45.

[19] D.M. Kolb, F. Forstmann, in: Matrix Isolation Spectroscopy, Eds. A.J. Barnes, W.J. Orville-Thomas, A. Muller, R. Gaufres, NATO ASI Series C, Vol. 76, D. Reidel, Dordrecht, The Netherlands 1981, p. 350.

[20] S. Pilla, J.A. Hameda, K.A. Muttalib, N.S. Sullivan, Phys. Lett. A 256, 75 (1999).

[21] G. Herzberg, Molecular Spectra and Molecular Structure I. Diatomic Molecules, 2nd ed., Van Nostrand, New York 1950, p. 534.

[22] E.L. Wagner, D.F. Hornig, J. Chem. Phys. 18, 305 (1950).

[23] W.C. Hamilton, J.A. Ibers, Hydrogen Bonding in Solids, W.A. Benjamin, Inc., New York 1961, p. 224-6. 